\title{
Transient Intrauterine Hypotension Causes Apoptosis in Fetal Rat Brain and Affects Learning
}

\author{
MERYEM TOMBAKOGLU, MURAT DURAKOGLUGIL, GÜLSEV KALE, HAKAN S. ORER, \\ ALMILA BULUN, AND BANU ANLAR
}

\author{
Departments of Pediatric Neurology [M.T., B.A.], Pharmacology [M.D., H.S.O.], and Pediatrics, Pediatric \\ Pathology Unit [G.K., A.B.], Hacettepe University, Ankara, Turkey 06100
}

\begin{abstract}
ABSTR
Hypotensive episodes are frequent during pregnancy, and
their functional effect on fetal brain has not been studied. We
produced systemic hypotension for 30 min during mid-gestation
in pregnant rats and examined their offspring on postnatal days 1
and 28. When compared with sham controls, the brain of the
hypotensive group contained more TUNEL-positive cells in the
hippocampal and periventricular regions on both time points.
Spatial learning assessed by water milk maze test was impaired
in 28-day-old pups of the hypotensive mothers. According to
these results, transient maternal hypotension can induce apopto-
tic cell death in fetal brain and affect learning. Similar mecha-
nisms may be considered and investigated in the pathogenesis of
human learning disorders. (Pediatr Res 53: 977-982, 2003)
\end{abstract}
Maternal, fetal, or placental factors that diminish uteroplacental and fetal circulation are associated with an increased incidence of fetal CNS malformations (1-3). While marked intrauterine perfusion failure might be related to major malformations, less severe or shorter hypoperfusion may take part in the pathogenesis of minor or functional cerebral disturbances. A frequent cause of hypoperfusion in pregnant women is hypotension: uteroplacental blood flow is known to diminish at blood pressures below 110/65 mm Hg. Hypotension may occur spontaneously, but is most frequently induced by position or drug treatment (4-6). Orthostatic hypotension in late pregnancy was found to be associated with low birth weight $(7,8)$. Although hypotension is considered potentially harmful for the fetus, its symptoms may be unnoticed or disregarded in pregnancy, and little clinical evidence exists on the effects of moderate and transient hypotension. In our previous experi-

Received December 31, 2001; accepted July 1, 2002.

Correspondence: Banu Anlar, M.D., Hacettepe University, Department of Pediatric Neurology, 06100 Ankara, Turkey; e-mail: banlar@hacettepe.edu.tr

This study was supported by Hacettepe University Research Fund and the Turkish Child Neurology Society, Ankara, Turkey.

Current address [M.T.]: Kırıkkale University, Department of Pediatrics, Kırıkkale, Turkey 71100 .

DOI: 10.1203/01.PDR.0000061562.67041.C0 ments simulating hypotensive episodes encountered in pregnant women, we reported that transient maternal hypotension increased apoptotic cell death in the fetal brain (9). In the current study, we investigated the effect of intrauterine hypotensive episodes on cognitive functions in addition to morphologic features.

\section{METHODS}

Gestational hypotension. Ten 3-mo-old pregnant Wistar rats were included in the study: on the 15th day of pregnancy, five were subjected to transient hypotension by femoral artery catheterization (hypotension group) and five underwent all procedures except hypotension (control group) as described before (9). According to preliminary experiments this was associated with an average $46 \%$ reduction in uterine blood flow. Briefly, rats were anesthetized following an overnight fasting by intraperitoneal $30 \mathrm{mg} / \mathrm{kg}$ ketamine (Ketalar ${ }^{\circledR}$, Eczacibasi, Istanbul) and $8 \mathrm{mg} / \mathrm{kg}$ xylazine (Rompun ${ }^{\circledR}$, Bayer, Istanbul), the left femoral artery was catheterized, blood pressure (BP) was recorded using a pressure transducer (Transbridge W P I, Sarasota, FL, U.S.A.) and data were sent to computer via MacLab 4/s data acquisition unit (AD instruments, Castle Hill, Australia). Heart rate (HR) and mean BP 
were monitored online using computer software in which the built-in module calculates the mean BP as the sum of $1 / 3$ of systolic and 2/3 of diastolic pressure (Chart v.3.5, Castle Hill, Australia). After a fluctuation and stable BP was obtained, blood was slowly drawn into a heparinized syringe until a $30-40 \mathrm{~mm} \mathrm{Hg}$ reduction in BP from baseline was obtained (approximately $0.8 \mathrm{~mL}$ per $100 \mathrm{~g}$ body weight). This syringe was kept at $37^{\circ} \mathrm{C}$. The lowered BP level was maintained for 20 min, equivalent to $6-7 \mathrm{~h}$ in human pregnancy. At the end of this period, blood was slowly re-infused in $10 \mathrm{~min}$ and the femoral artery was ligated. Control rats were subjected to the whole procedure except blood withdrawal. Both groups were left to complete the normal course of pregnancy. The study was approved by the Hacettepe University Animal Ethics Committee.

Histopathological examination, TUNEL method. Newborn pups were weighed on their first day, examined for general appearance or malformations, and numbered. Brains were examined at two time points: in the first $24 \mathrm{~h}$ of life $(n=5)$, and on postnatal day $28(n=5)$. At each time point, one pup was randomly chosen from each mother's litter using the table of random numbers and decapitated. The brain was fixed in $10 \%$ buffered formalin, embedded in paraffin, and two consecutive $1.5 \mu \mathrm{m}$ coronal midtemporal sections were taken (Fig. 1).

Examination with hematoxylin-eosin (H\&E) was done under $40 \times$ magnification for cortical architecture, ventricular integrity, and the presence of tissue destruction and hemorrhage. Cellular necrotic changes, defined as cytoplasmic swelling, vacuolation, eosinophilic staining, shrinkage, and lysis of nucleus or cytoplasm, were graded as: Grade I: minimal neuronal changes, Grade II: loss of one or more neurons in one area, Grade III: neuronal loss in more than one area. Hemorrhage was classified as intraparenchymal/petechial, periventricular/intraventricular, and leptomeningeal. The presence of edema was noted according to its location.

DNA fragmentation was evaluated by the TUNEL method (ApopTag Kit, Appligene Oncor, France) (10). Briefly, poly1-lysine coated slides were deparaffinized, hydrated in decreasing concentrations of ethanol, incubated with proteinase $\mathrm{K}$, and endogenous peroxidase was blocked in $35 \%$ hydrogen peroxide. Nick-end labeling was carried out with digoxygenin-dUTP and TdT followed by peroxidase-conjugated anti-digoxygenin. Visualization was done with $0.05 \%$ diaminobenzidine and background staining, with methyl green. TUNEL-positive cells identified as brownish cells showing intense nuclear staining, shrinkage, peripheral condensation, and nuclear fragmentation, were initially screened and located in all the section under low magnification $(\times 100)$, then counted in all areas of two adjacent coronal sections under high magnification $(\times 400)$ by two blinded examiners, and the average was recorded.

Cognitive tests: water milk maze test. The water milk maze test (WMM), an indicator of spatial learning and working memory functions, was used to evaluate 28-d-old rats (11). One young rat from each mother, therefore five from the hypotensive and five from the control group were subjected to the test. Briefly, a cylindrical container of 1-m diameter was filled to a final depth of $33 \mathrm{~cm}$ with water opacified with milk. A transparent plastic platform was fixed $2 \mathrm{~cm}$. below the liquid

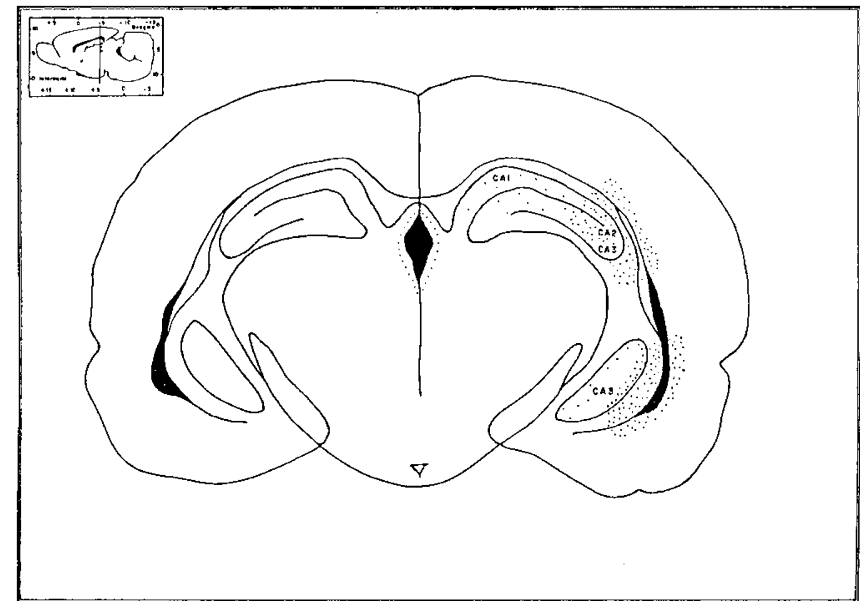

Figure 1. Level of coronal section (inset), diagram of the area examined and location of TUNEL-positive cells.

level. Rats were released at the opposite pole of the container and allowed one minute to find and climb over the submerged platform. Each rat was tested 5 times/d on three consecutive days, therefore undergoing a total of 15 tests. All experiments were performed at the same hour every day and were recorded by a video camera. The following parameters were measured and evaluated by two blinded examiners who watched the video recording subsequently: 1) time needed to reach the platform, 2) length of itinerary toward the platform, 3) motor activity, strength, and symmetry in body movements.

Statistical analysis. Mann-Whitney U test was used for comparison of cell counts. Correlation analysis between TUNEL-positive cell counts and time to platform was assessed by Statview software program (version 4.3, Abacus Concepts, Berkeley, CA, U.S.A.). WMM test results were analyzed by ANOVA.

\section{RESULTS}

Hypotension and control groups were similar in terms of average weight, duration of gestation, and litter size (Table 1). No stillbirths, neonatal deaths, major malformations, or low birth weight were observed in either group.

Table 1. Weight, duration of gestation and litter size of the rat groups

\begin{tabular}{lccc}
\hline \multicolumn{1}{c}{ Rat No. } & Weight $(\mathrm{g})$ & $\begin{array}{c}\text { Duration of } \\
\text { gestation }(\text { days })\end{array}$ & Litter size \\
\hline Hypotension $(n=5)$ & & & \\
H1 & 254 & 25 & 4 \\
H2 & 260 & 23 & 9 \\
H3 & 260 & 23 & 6 \\
H4 & 286 & 24 & 8 \\
H5 & 264 & 24 & 7 \\
Average $( \pm$ SD) & $264.8 \pm 14.3$ & $23.8 \pm 0.8$ & $6.8 \pm 2.0$ \\
Control $(n=5)$ & & & \\
C1 & 275 & 23 & 5 \\
C2 & 320 & 25 & 11 \\
C3 & 320 & 24 & 9 \\
C4 & 240 & 23 & 8 \\
C5 & 265 & 24 & 7 \\
Average $( \pm$ SD) & $284 \pm 38$ & $23.8 \pm 0.8$ & $8 \pm 2.2$ \\
\hline
\end{tabular}


Changes in hemodynamic parameters of pregnant rats during the surgical procedure are given in Table 2. There were no significant BP and HR changes in the control group. Blood withdrawal produced significant hypotension accompanied by a mild, nonsignificant decrease in HR in the hypotensive group $(p<0.05)$.

Histopathology. Neonatal rat brains revealed no hemorrhage, inflammation, or alteration of cortical layering. Grade 1 necrosis was present in some rats from each group, but Grade 2 necrosis was seen only in the hypotension group, on day 1 or day 28. Grade 3 necrosis was absent in both groups (Table 3 ).

The number of TUNEL-positive cells showing nuclear condensation, blebbing and fragmentation was significantly higher in the hypotension group, both on day 1 and day 28 (Table 3). This group also showed a concentration of TUNEL-positive cells in the periventricular and hippocampal areas, including parts of CA2 and CA3, compared with other cerebral regions $(p=0.009)$ while control rats did not show any regional difference (Figs. 1, 2a-d).

Water milk maze test. Animals in the two groups displayed similar motor activity and swimming performance on the first test day, and spent equal time to find the platform. However, on second and third test days, the hypotensive group persisted in longer and circular itineraries to reach the platform while the route of the control group became progressively shorter over 15 trials. The difference between group times to platform was significant on the second test day $(p=0.05)$ and more so on the third test day $(p=0.02)$ (Table 4$)$. The correlation between cognitive performance and apoptosis was evaluated by plotting the average time to platform of each 28-day-old rat against the number of apoptotic cell counts obtained from its littermate. The correlation between the decline in cognitive performance and the increase in the number of apoptotic cells was statistically significant $(p<0.05)$ in hypotensive animals but not in the control group $(p>0.05)$ (Fig. $3 a, b)$.

\section{DISCUSSION}

The effects of the hypotensive episode applied in the present study were subclinical, as no major malformations, growth retardation, or stillbirths were observed in the fetus. Increased apoptosis was found particularly in the hippocampal region and correlated with a clinical observation, impairment of spatial learning. In a study by Cai et al. rat fetuses were subjected to deeper hypoxia-ischemia by clamping of uterine vasculature for $30 \mathrm{~min}$ on gestation day 17 . These animals showed diminished learning ability at $28 \mathrm{~d}$ of age in the Morris water maze test. A reduction in expression of NOS mRNA and NOS activity in the hippocampus was observed, but histopathology or apoptosis were not investigated (12). Nitric oxide has inhibitory or activatory effects on different pathways of apoptosis and necrosis, and might have played a role in the apoptosis observed in our study as well $(13,14)$. Necrotic changes were only slightly increased in our experimental group. Longer and deeper hypotension could have resulted in more extensive necrosis and less apoptosis because hypoxic or toxic insults

Table 2. Hemodynamic parameters during experiment

\begin{tabular}{|c|c|c|c|c|c|}
\hline Rat No. & $\begin{array}{c}\text { Baseline MBP } \\
(\mathrm{mm} \mathrm{Hg})\end{array}$ & Baseline HR & $\begin{array}{l}\text { Blood drawn } \\
(\mathrm{ml})\end{array}$ & Exp. MBP & Exp. HR \\
\hline \multicolumn{6}{|l|}{ Hypotension } \\
\hline H1 & 90 & 260 & 2 & 53 & 250 \\
\hline $\mathrm{H} 2$ & 100 & 250 & 2 & 61 & 290 \\
\hline $\mathrm{H} 3$ & 93 & 284 & 2.6 & 56 & 206 \\
\hline $\mathrm{H} 4$ & 82 & 354 & 2.3 & 53 & 242 \\
\hline H5 & 90 & 300 & 2 & 60 & 290 \\
\hline Average $( \pm \mathrm{SD})$ & $91 \pm 6.4$ & $289.6 \pm 41$ & $2.18 \pm 0.3$ & $56.6 \pm 3.8$ & $255.6 \pm 35.6$ \\
\hline \multicolumn{6}{|l|}{ Control } \\
\hline C1 & 80 & 330 & - & 75 & 335 \\
\hline $\mathrm{C} 2$ & 100 & 275 & - & 100 & 280 \\
\hline $\mathrm{C} 3$ & 105 & 340 & - & 100 & 340 \\
\hline $\mathrm{C} 4$ & 90 & 280 & - & 80 & 270 \\
\hline $\mathrm{C} 5$ & 95 & 290 & - & 95 & 280 \\
\hline Average $( \pm \mathrm{SD})$ & $94 \pm 9.6$ & $303 \pm 30$ & & $90 \pm 11.8$ & $301 \pm 33.6$ \\
\hline
\end{tabular}

MBP, mean blood pressure; HR, heart rate; Exp., experimental.

Table 3. Number of pups having necrosis (n) and TUNEL-positive cell counts on postnatal day 1 (PD1) and day 28 (PD28)

\begin{tabular}{|c|c|c|c|c|c|}
\hline \multirow[b]{2}{*}{ Groups } & \multicolumn{3}{|c|}{ Cellular necrosis $(n)$} & \multirow[b]{2}{*}{$\begin{array}{c}\text { No necrosis } \\
(n)\end{array}$} & \multirow[b]{2}{*}{$\begin{array}{l}\text { TUNEL-positive cells } \\
\quad(\text { mean } \pm \text { SD })\end{array}$} \\
\hline & $\begin{array}{c}\text { GRADE } \\
1\end{array}$ & $\begin{array}{c}\text { GRADE } \\
2\end{array}$ & $\begin{array}{c}\text { GRADE } \\
3\end{array}$ & & \\
\hline PD1 & 3 & 2 & - & - & $263 \pm 73.2^{*}$ \\
\hline PD28 & 4 & - & - & 1 & $37.8 \pm 15.5^{* *}$ \\
\hline \multicolumn{6}{|l|}{ Control } \\
\hline
\end{tabular}

$* p<0.05$ compared to PD1 control value.

** $p<0.05$ compared to PD28 control value. 

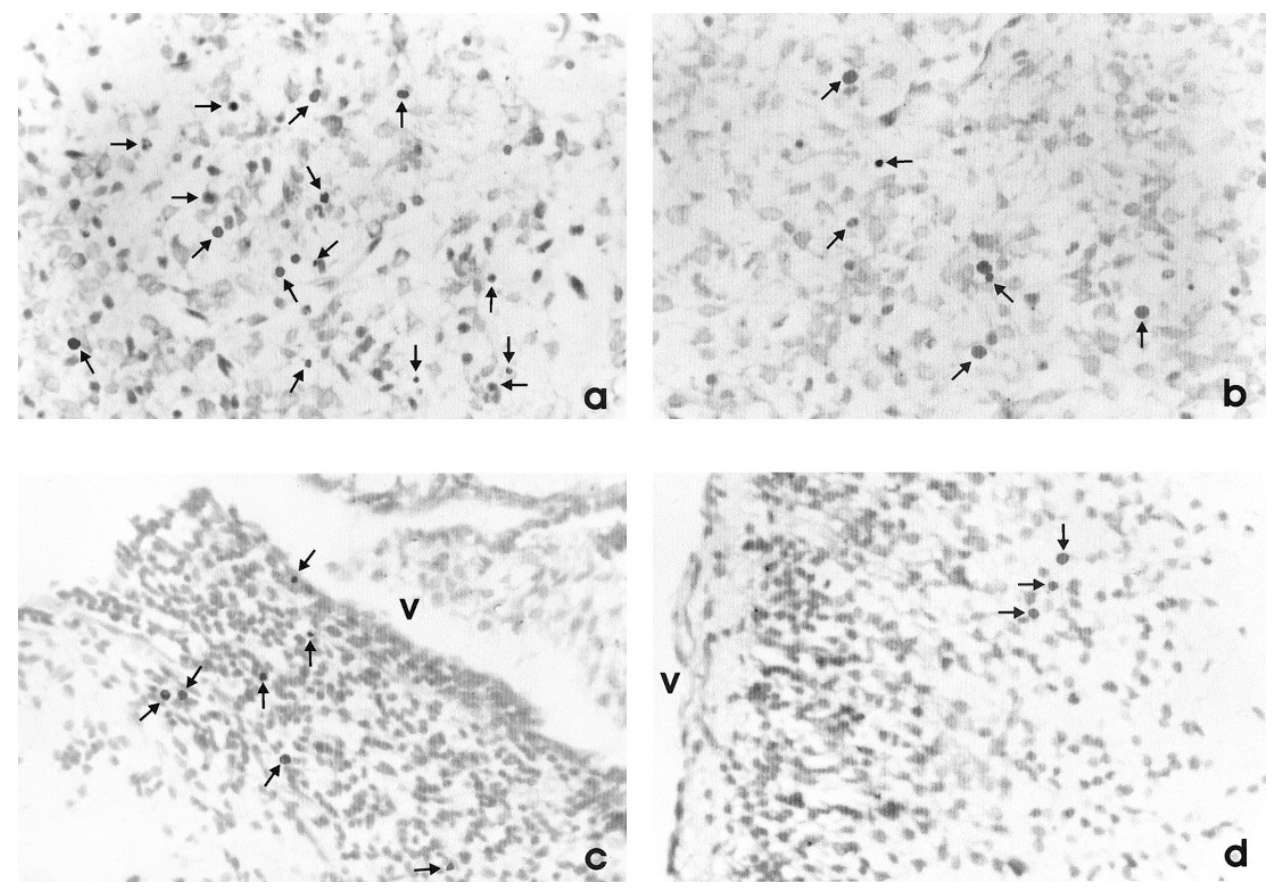

Figure 2. Coronal section, TUNEL positive cells in the periventricular germinative zone. (a) Hypotension group, postnatal day 1, (b) Control group, postnatal day 1, (c) Hypotension group, postnatal day 28, (d) Control group, postnatal day 28. A larger number of apoptotic cells, some with condensed nuclei, are observed at the same location in $(a)$ and $(c)$ (some indicated by arrows). Areas covered by Figs. $2 a-d$ contain 16, 7, 7, and 3 apoptotic cells, respectively. V, ventricular cavity. (Original magnification $\times 40$, background: methyl green).

Table 4. Time to platform (s) of 28-day-old rats over three test days (each value is the mean of five tests)

\begin{tabular}{lcccc}
\hline Rat No. & Test day 1 & Test day $2^{*}$ & Test day $3^{* *}$ & Tests mean \pm SD \\
\hline Hypotension 1 & 18.62 & 18.2 & 6.6 & $14.47 \pm 6.81$ \\
Hypotension 2 & 33.42 & 22.43 & 8.2 & $21.42 \pm 12.53$ \\
Hypotension 3 & 29.2 & 16.2 & 13.2 & $17.87 \pm 10.60$ \\
Hypotension 4 & 40.8 & 41.6 & 9.2 & $31.87 \pm 16.17$ \\
Hypotension 5 & 12.8 & 15.6 & $9.12 \pm 2.46$ & $12.53 \pm 3.21$ \\
Average \pm SD & $26.97 \pm 11.28$ & $22.81 \pm 10.84$ & 7 & $19.63 \pm 2.49$ \\
Control 1 & 21.68 & 17.6 & 6.4 & $15.43 \pm 7.58$ \\
Control 2 & 20.2 & 21.2 & 5.4 & $15.87 \pm 8.39$ \\
Control 3 & 12.4 & 11.4 & 5.4 & $10.07 \pm 3.21$ \\
Control 4 & 10.2 & 8.2 & $7.93 \pm 2.41$ \\
Control 5 & 24.6 & $13.32 \pm 5.8$ & $6.08 \pm 0.6$ & $12.73 \pm 10.37$ \\
Average \pm SD & $17.81 \pm 6.2$ & $12.4 \pm 2.11$ & 1 \\
\hline
\end{tabular}

$* p<0.05$ between averages of hypotension and control groups on test day 2 .

$* * p<0.001$ between averages of hypotension and control groups on test day 3 .

cause different types of cell death depending on a dose effect: lower exposure is usually associated with apoptosis, and higher doses, with necrosis (15).

Spatial learning is primarily a function of the hippocampus and is affected by lesions of this area $(16,17)$. The predominant involvement of the hippocampal region in our study may be related to the developmental stage of the fetus on embryonic day 15 , developing structures being more sensitive to injury: the mid-gestational period coincides with cortical and particularly hippocampal development in the rat. In addition, the hippocampus appears to have a particular susceptibility to injury owing to its vasculature, its content of NMDA receptors, or intracellular ATP (18-20).

A question may arise about the interval between the insult and the observation of apoptosis, which was 1 week in our study. Protracted or delayed apoptosis has previously been described following trauma, ischemia, or in cultured cells deprived of trophic factors: apoptotic cells can be detected for days or weeks after the hypoxic-ischemic insult $(21,22)$. This may be due to the fact that the observed apoptosis is secondary to the death of other cells providing survival signals such as substrate or growth factor support. This hypothesis will be evaluated in further studies by following the time course of histopathological changes on consecutive days after hypotension is applied.

Another point of discussion is the method used to detect apoptosis. We used the TUNEL method in combination with morphologic criteria, as done in most studies cited above. All methods used for apoptosis have certain limitations: electron microscopy, accepted as the gold standard for the definition of 


\section{HYPOTENSION}

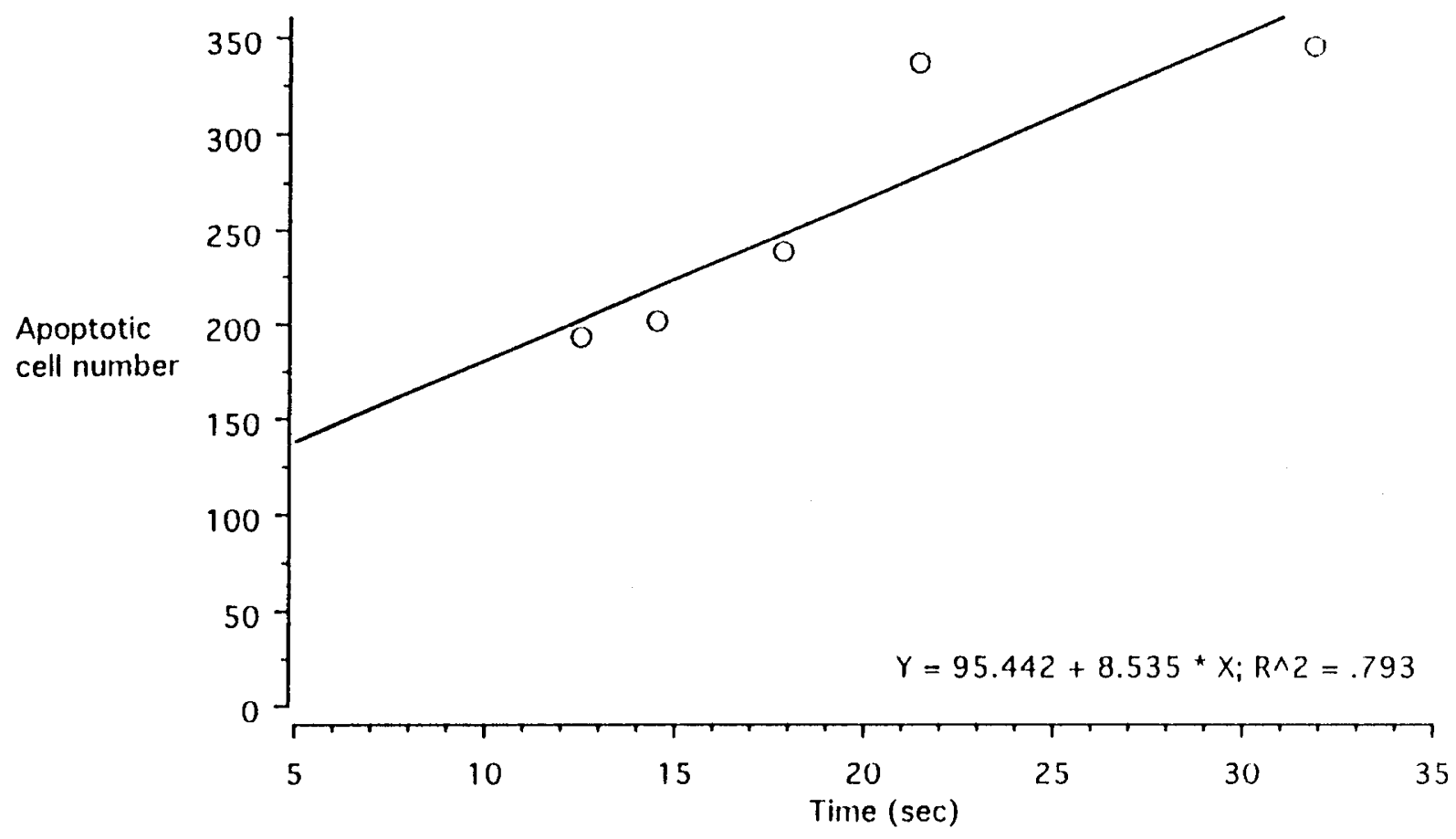

\section{CONTROL}

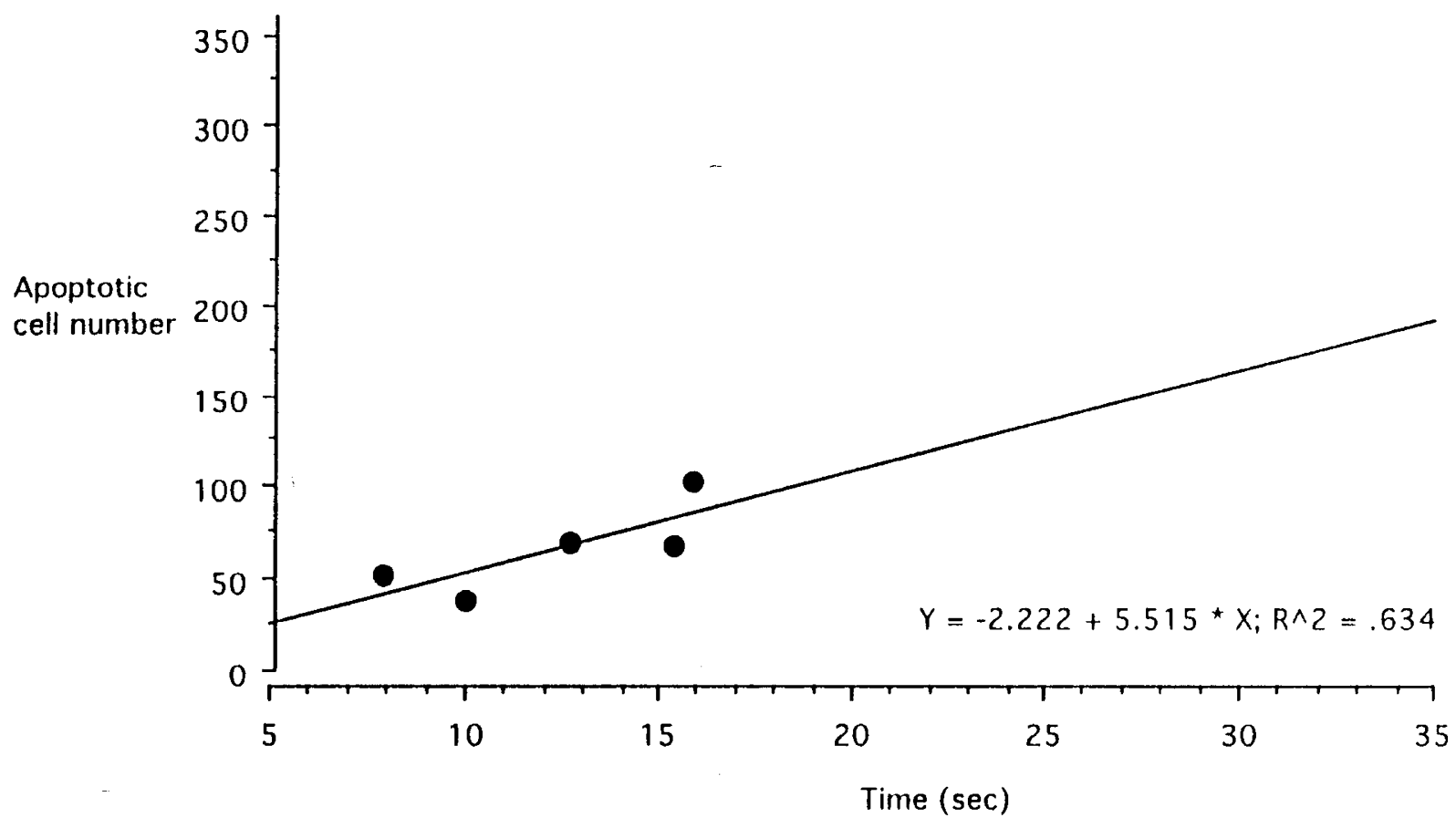

Figure 3. Graph correlation analysis of time to reach platform and total number of apoptotic cells in the hypotension group (top) and control group (bottom). Mean values of the number of apoptotic cells and the time to reach platform are shown in Tables 3 and 4, respectively.

the apoptotic cell, is not suitable for screening tissue samples, and DNA laddering does not allow histopathological localization of findings. A combination of staining methods and morphology are recommended whenever feasible.
Our results suggest learning difficulties and attention problems occurring in the absence of cerebral malformations or destructive lesions could be associated with more subtle histologic abnormalities. The age we observed these changes, 
postnatal day 28, corresponds to early childhood in humans, an age where learning problems come to attention. Learning disorders comprise a heterogeneous group of developmental problems involving various cognitive functions at different degrees. They are considered of constitutional origin, and genetic or environmental events resulting in abnormalities in the maturation of the cerebral cortex or subtle differences in brain anatomy have been suggested in their etiology (23). The results of our study imply that prenatal events could produce such findings. According to statistical data, prenatal hemorrhage, among many other factors, can be associated with learning difficulty (24). Future studies on the etiology of developmental disorders should include prospective follow-up of pregnancies with altered blood pressure, and a detailed assessment of the prenatal period for various, sometimes subclinical events resulting in fetal hypoperfusion.

\section{REFERENCES}

1. Evrard P, Belpaire MC, Boog G, Elkhazen N, Gadisseux JF, LeMarec B, Misson JP Santini JJ, Van Lierde M 1985 Diagnostic anténatal des affections du systeme nerveux central: résultats préliminaires d'une étude multicentrique européenne. J Fr Echogr $2: 123-126$

2. Stewart RM, Richman DP, Caviness VS Jr 1975 Lissencephaly and Pachygyria: an architectonic and topographical analysis. Acta Neuropathol (Berl) 31:1-12

3. Ornoy A, Benady S, Kohen-Raz R, Russell A 1975 Association between maternal bleeding during gestation and congenital anomalies of the offspring. Am J Obstet Gynecol 124:474-478

4. Ikeda T, Ohbuchi H, Ikenoue T, Mori N 1992 Maternal cerebral hemodynamics in the supine hypotensive syndrome. Obstet Gynecol 79:27-31

5. O'Grady JP, Parker RK, Patel SS 2000 Nitroglycerin for rapid tocolysis: development of a protocol and a literature review. J Perinatol 20:27-33

6. Impey L 1993 Severe hypotension and fetal distress following sublingual administration of nifedipine to a patient with severe pregnancy induced hypertension at 33 weeks. Br J Obstet Gynaecol 100:959-961

7. Grunberger W, Leodolter S, Parschalk O 1979 Maternal hypotension: fetal outcome in treated and untreated cases. Gynecol Obstet Invest 10:32-38
8. Hohmann M, Kunzel W 1991 Orthostatic hypotension and birthweight. Arch Gynecol Obstet 248:181-189

9. Apak RA, Anlar B, Atilla P, Çakar N 2001 Transient intrauterine hypotension: effect on newborn rat brain. Pediatr Res 49:45-49

10. Gavrieli Y, Sherman Y, Ben-Sason SA 1992 Identification of programmed cell death in situ via specific labeling of nuclear DNA fragmentation. J Cell Biol 119:493-501

11. Morris RGM, Garrud P, Rawlins JNP, O'Keefe J 1982 Place navigation impaired in rats with hippocampal lesions. Nature 297:681-683

12. Cai Z, Xiao F, Lee B, Paul IA, Rhodes PG 1999 Prenatal hypoxia-ischemia alters expression and activity of nitric oxide synthase in the young rat brain and causes learning deficits. Brain Res Bull 49:359-365

13. Kim PK, Zamora R, Petrosko P, Billiar TR 2001 The regulatory role of nitric oxide in apoptosis. Int Immunopharmacol 1:1421-1441

14. Kroncke KD, Fehsel K, Suschek C, Kolb-Bachofen V 2001 Inducible nitric oxide synthase-derived nitric oxide in gene regulation, cell death and cell survival. Int Immunopharmacol 1:1407-1420

15. Bonfoco E, Krainc D, Ankarcrona M, Nicotera P, Lipton SA 1995 Apoptosis and necrosis: two distinct events induced, respectively, by mild and intense insults with $\mathrm{N}$-methyl-D-aspartate or nitric oxide/superoxide in cortical cell cultures. Proc Natl Acad Sci USA 92:7162-7166

16. Steffenach HA, Sloviter RS, Moser EI, Moser MB 2002198 Impaired retention of spatial memory after transection of longitudinally oriented axons of hippocampal CA3 pyramidal cells. Proc Natl Acad Sci USA 99:3194-3193

17. Gerlai RT, McNamara A, Williams S, Phillips HS 2002 Hippocampal dysfunction and behavioral deficit in the water maze in mice: an unresolved issue? Brain Res Bull 57:3-9

18. Bernal F, Saura J, Ojuel J, Mahy N 2000 Differential vulnerability of hippocampus, basal ganglia, and prefrontal cortex to long-term NMDA excitotoxicity. Exp Neurol 161:686-695

19. Zhao G, Flavin MP 2000 Differential sensitivity of rat hippocampal and cortical astrocytes to oxygen-glucose deprivation injury. Neurosci Lett 285:177-180

20. Moga D, Hof PR, Vissavajjhala PH 2002 Parvalbumin-containing interneurons in rat hippocampus have an AMPA receptor profile suggestive of vulnerability to excitotoxicity. J Chem Neuroanat 23:249-253

21. Conti AC, Raghupati R, Trojanowski JQ, McIntosh TK 1998 Experimental brain injury induces regionally distinct apoptosis during the acute and delayed posttraumatic period. J Neurosci 18:5663-5672

22. Sheth RD, Bodensteiner JB 1998 Delayed postanoxic encephalopathy: possible role for apoptosis. J Child Neurol 13:347-348

23. Habib M 2000 The neurological basis of developmental dyslexia: an overview and working hypothesis. Brain 123 Pt 12:2373-2399

24. Milberger S, Biederman J, Faraone SV, Guite J, Tsuang M 1997 Pregnancy, delivery and infancy complications and attention deficit hyperactivity disorder: issues of gene-environment interaction. Biol Psychiatry 41:65-75 